(2) Open Access Full Text Article

REVIEW

\title{
Stem cell-mediated osteogenesis: therapeutic potential for bone tissue engineering
}

This article was published in the following Dove Press journal:

Biologics:Targets and Therapy

9 March 2012

Number of times this article has been viewed

Josh Neman'

Amanda Hambrecht ${ }^{2}$

Cherie Cadry ${ }^{3}$

Rahul Jandial'

'Department of Neurosurgery, Beckman Research Institute, City of Hope National Cancer Center, Duarte, ${ }^{2}$ Department of Biological Sciences, University of Southern California, Los Angeles, ${ }^{3}$ Department of Public Health Sciences, University of California, Irvine, California, USA

Correspondence: Rahul Jandial City of Hope, 1500 East Duarte Road, Duarte, CA 91010 , USA

Tel +l 6262564673

Fax +I 6269305330

Email rjandial@coh.org
Abstract: Intervertebral disc degeneration often requires bony spinal fusion for long-term relief. Current arthrodesis procedures use bone grafts from autogenous bone, allogenic backed bone, or synthetic materials. Autogenous bone grafts can result in donor site morbidity and pain at the donor site, while allogenic backed bone and synthetic materials have variable effectiveness. Given these limitations, researchers have focused on new treatments that will allow for safe and successful bone repair and regeneration. Mesenchymal stem cells have received attention for their ability to differentiate into osteoblasts, cells that synthesize new bone. With the recent advances in scaffold and biomaterial technology as well as stem cell manipulation and transplantation, stem cells and their scaffolds are uniquely positioned to bring about significant improvements in the treatment and outcomes of spinal fusion and other injuries.

Keywords: mesenchymal stem cell, osteogenesis, scaffolds, bone morphogenetic protein, Wnt, autograft, osteoblast

\section{Introduction}

Intervertebral disc degeneration remains a pervasive and intractable disease arising from a combination of aging and stress on the bony and cartilaginous elements of the spinal column. ${ }^{1}$ Some patients will have disease progression that, despite conservative and minimally invasive therapies, requires arthrodesis (fusion) of particular spinal segments as the direct treatment of pathological pain-generating motion, or in stabilization after the decompression of symptomatic neural elements. As spinal instrumentation has evolved over the last decade, the role that surgery plays in the treatment of degenerative spinal pathology has increased. Critical to achieving a durable repair of the spine, arthrodesis depends heavily on the quality and quantity of autograft bone or bone substitutes. The ideal bone graft substitute should provide the benefits afforded by autograft (successful physiological fusion), thus allowing surgical intervention to be successful without the risk of donor site morbidity from autograft harvesting.

Regenerative medicine attempts to repair, regenerate, or replace tissues damaged by factors such as injury or disease. ${ }^{2}$ This growing field of medicine brings the promise of stem cells in the improvement of fusion options. In this pursuit, advancements in osteogenesis through the use of mesenchymal stem cells (MSCs) may provide the fundamental components that comprise autograft: osteoconductive scaffolds, osteoinductive signals, and osteogenic cells. Given the recent advances in minimally invasive spine surgery and the developing body of work on stem cell manipulation 
and transplantation, stem cells are uniquely poised to bring about large-scale improvements in treatment and outcomes of spinal fusion and other injuries. However, there are fundamental unresolved issues in the therapeutic use of stems cells; namely, the percentage and quantity of cells that are phenotypically MSCs remain to be discovered. These cells are most likely the "engine" that makes the bone heal. Essential to providing evidence toward the efficacy of MSCmediated osteogenesis and bone healing is the evaluation of the gene expression profile and protein determination of MSCs and their cellular osteogenic progeny.

\section{Natural bone healing cascade}

Osteogenesis occurs throughout life, is involved in bone remodeling in adults, and is activated in injuries including, but not limited to, fractures of the bone. ${ }^{3,4}$ Bone formation depends on the cooperation of four factors: (1) specific cell types such as MSCs, osteoblasts, and osteoclasts; (2) the scaffold (hydroxyapatite, extracellular matrix molecules); (3) expression of soluble molecules (cytokines, growth factors, hormones, ions, vitamins); $3,5,6$ and (4) various mechanical stimuli. ${ }^{3,7}$ Normal development of the skeleton during embryogenesis occurs by intramembranous and endochondral ossification. ${ }^{3,8}$

Osteoblasts secrete the growth factors and deposit the matrix necessary for osteogenesis, while osteoclasts function in bone remodeling. ${ }^{9}$ Skeletal stability is reached by focal osteoclast-mediated degradation and osteoblast-mediated formation, while the overall architecture and anatomy of bones is maintained. Thus, the amount of new bone equals the amount resorbed, with no net change in the volume of bone. ${ }^{10}$ As a consequence, new calcium phosphate crystals replace the less soluble and mature mineral crystalline component of bone. ${ }^{10}$ Therefore, the molecular remodeling and composition of the adult skeleton is a dynamic process that changes as a new bone fills each resorbed site. ${ }^{10}$ Moreover, the renewal of bone matrix is central for the essential role that bone has in mineral exchange and homeostasis. ${ }^{10}$

\section{The MSC component}

In the adult stages, MSCs contribute to the maintenance of various tissues, particularly those of the bone. ${ }^{3}$ MSCs can be isolated from bone marrow and adipose tissues in adult stages and from placenta and umbilical cord blood. ${ }^{3,11}$ MSCs can be induced in vitro and in vivo to differentiate into various mesenchymal tissues such as bone, cartilage, muscle, tendon, adipose tissue, and hematopoiesis-supporting stroma. ${ }^{3}$ MSCs are selected by their capacity for adherence to plastic culture flasks and then expand via colony-forming unit fibroblasts after several weeks in vitro. ${ }^{3,11}$ However, this procedure does not permit characterization of the native form, whereas extensive work has described the in vitro-derived phenotype and multipotentiality of cultured MSCs. ${ }^{3}$ Recent studies have clearly demonstrated that native-form MSCs are phenotypically and functionally different from cultured MSCs and similar to perivascular cells. ${ }^{3}$ Under in vitro conditions, cultured MSCs can be characterized as nonhematopoietic cells (CD14-, CD34-, and CD45-) and express several surface markers such as CD44, CD106, CD146, and CD166. ${ }^{3}$ Cultured MSCs are largely used in experimental bone reconstruction in vivo and in vitro..$^{3,11,12}$ The cells are generally cultured in basal medium such as Dulbecco's modified Eagle's medium with $10 \%$ fetal bovine serum. ${ }^{11,13}$ Researchers believe that serum components in fetal bovine serum play crucial roles in the attachment and proliferation of MSCs. ${ }^{14}$ Osteogenic activation requires the presence of $\beta$-glycerol-phosphate, L-ascorbic acid-2 phosphate, dexamethasone, and fetal bovine serum. ${ }^{13,15}$ A study by Jaiswal et al found that optimal osteogenic differentiation was achieved with Dulbecco's modified Eagle's medium-base medium plus $100 \mathrm{nM}$ dexamethasone, $0.05 \mathrm{mM}$ L-ascorbic acid-2 phosphate, and $10 \mathrm{mM} \beta$-glycerol-phosphate. ${ }^{15}$ Although few human clinical studies have investigated improvements in either bone defects or osteogenesis imperfecta disease, clinical studies, with related controls, are needed to confirm the potential of cultured MSCs, regardless of origin (allogeneic or autologous), for use in bone tissue engineering in the clinic. ${ }^{3}$

\section{MSC derivation}

The limiting factor in exploiting stem cells for therapeutic use is obtaining well characterized cells for transplantation. ${ }^{1}$ Several researchers have demonstrated that colonies derived from colony-forming unit fibroblast assays are heterogeneous in appearance and size as well as differentiation potential. ${ }^{16-18}$ Studying the activity of MSCs is made difficult by the lack of unique identifying markers, and therefore an inconsistency in molecular expression. ${ }^{2,19-21}$ Consequently, directing the appropriate differentiation of both native-form MSCs and cultured MSCs is a complex molecular and cellular riddle that is dependent upon not only the inherent properties of cells but also the environment in which they are cultured. ${ }^{1}$ The soluble growth factors, transforming growth factor beta and bone morphogenetic proteins (BMPs), are the necessary components of in vitro culture media used to induce chondrogenic and osteogenic differentiation of MSCs. ${ }^{1}$ 
In fact, careful use of soluble factors in media can lead to chondrogenesis and osteogenesis with a genetic profile similar to intervertebral disc tissue, rather than articular cartilage. $^{1,22}$

Another method exploits the MSCs' microenvironment and triggers differentiation by coculturing with different cell populations to take advantage of cell-cell contact and activation. ${ }^{1}$ Utilizing the autocrine and paracrine factors secreted by one cell type leads to the activation of cell surface receptors on MSCs. ${ }^{1}$ Experiments culturing human neural progenitor cells and MSCs found that differentiation was reliant on cell-cell contact by looking at gene expression of Sox9, type II collagen, and aggrecan., ${ }^{1,23}$

The three-dimensional properties of the culture system have also been shown to exert substantial influence on the process of cell fate determination. ${ }^{1}$ MSCs are pelleted down into a dense micromass in combination with transforming growth factor, BMP, and insulin-like growth factor growth factors, ${ }^{9}$ before addition of soluble factors to recreate the in vivo state that leads to cartilage formation. ${ }^{1}$ This structure helps direct the chondrogenic cascade of MSC differentiation from micromass into cartilage. ${ }^{1}$ Mesenchymal condensation allows for extracellular signaling molecules, such as Wnt glycoproteins and N-cadherin, to form cadherin and connexin adhesion complexes for the beginning stages of extracellular matrix formation. ${ }^{1}$ Cartilage then begins to form on this three-dimensional scaffold. ${ }^{1}$ Plating density of MSCs prior to soluble factor addition also influences the efficiency of differentiation. ${ }^{1}$ This is because plating density can change the cell morphology; specifically, wider spindleshaped cells correspond with denser MSCs plating. ${ }^{1}$ Wider cells also have an increased propensity to differentiate after exposure to soluble factors in vitro. ${ }^{1,24}$ In this way, employing density-dependent culturing techniques can produce cartilage formation from MSCs in vitro, and increase the efficiency of MSC differentiation. ${ }^{1}$

It has been suggested that MSCs can be isolated from other tissues, but their similarity to those isolated from bone marrow in terms of potential for osteogenesis and chondrogenesis is not fully understood. Controversial cells from human umbilical cord blood and human derived-placenta cells have been extensively studied for MSC potential. An early study identified preterm cord blood as being rich in mesenchymal progenitor cells that displayed a fibroblast-like morphology and expressed several mesenchymal progenitor cell-related surface antigens. ${ }^{25}$ Another group later isolated human MSC-like adherent cells from human umbilical cord blood that could differentiate into a variety of mesenchymal lineage cells, including osteoblasts and chondrocytes, under the appropriate conditions. ${ }^{26}$ A related study identified MSClike cells in human placenta that possessed multilineage differentiation potential similar to MSCs under specific conditions. ${ }^{27}$ The less-controversial adipose tissue-derived MSCs have been previously shown to differentiate into bone, cartilage, fat, or muscle but have been found to have an inferior potential for both osteogenesis and chondrogenesis compared with bone marrow-derived MSCs. ${ }^{28}$

\section{Molecular mechanisms underlying bone healing}

Osteoblasts are cells of mesenchymal origin that secrete bone-matrix proteins and promote mineralization. ${ }^{29-31}$ The proliferation and differentiation of osteoblasts are under the control of a number of soluble factors and transcription factors such as runt-related transcription factor 2 (Runx2) and osterix (also known as Sp7). ${ }^{29,32,33}$ Differentiated osteoblasts embedded in the bone matrix are called osteocytes and might have a specific, but currently unclear, role in mechanotransduction. ${ }^{29,30}$ Osteoclasts are cells of hematopoietic origin that decalcify and degrade the bone matrix by acid decalcification and proteolytic degradation, respectively. ${ }^{29,34}$ They are large, multinucleated cells formed by the fusion of precursor cells of the monocyte-macrophage lineage. ${ }^{29}$

In vitro osteoclast differentiation is supported by mesenchymal cells (bone marrow stromal cells or osteoblasts) through cell-cell contact, ${ }^{29,35}$ although there has been little in vivo information about osteoclastogenesis-supporting cells. ${ }^{29}$ Osteoclastogenic signals are mediated by receptor activator of nuclear kappa-B ligand (RANKL) and its costimulatory signals, in addition to macrophage colony-stimulating factor 5 (Figure 1). ${ }^{29,36-38}$ The congenital lack of osteoclasts leads to osteopetrosis, which is characterized by a high bone mass and a defect in bone marrow formation. ${ }^{29}$ Naturally occurring mutant mice or genetically modified mice with osteopetrosis have provided insights into the molecular mechanism of osteoclast differentiation and function. ${ }^{29,39}$ Macrophage colony-stimulating factor and the transcription factor PU.1 are crucial for the proliferation and survival of osteoclast precursor cells; transcription factors such as cFOS, microphthalmia-associated transcription factor, and nuclear factor kappa-B have been shown to be essential for osteoclast differentiation; and factors such as cSRC, VAV3, $\beta 3$-integrin, chloride-channel family member $\mathrm{ClC}$, vacuolar adenosine triphosphatase, and cathepsin $\mathrm{K}$ are crucial for osteoclast function (Figure 2)..$^{29,39}$ 
A Generation of osteoclast precursor cells by M-CSF

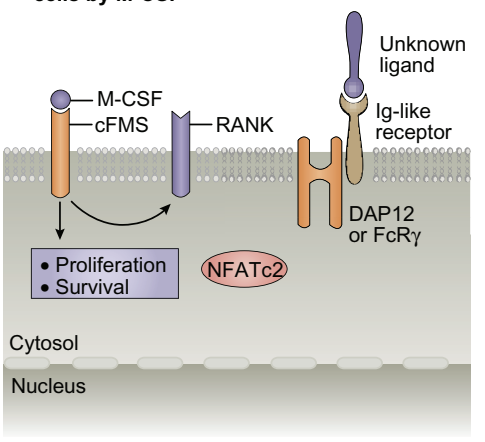

B Early response to RANKL

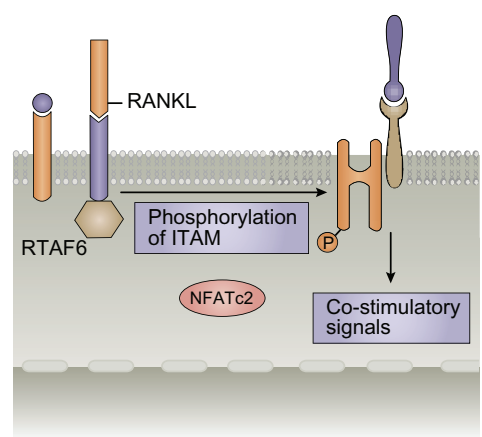

C Initial induction of NFATc1

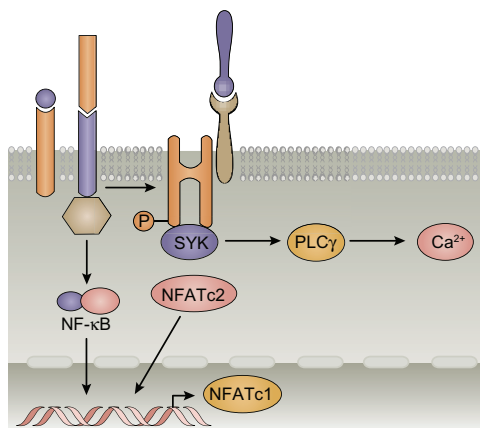

D Autoamplification of NFATc1

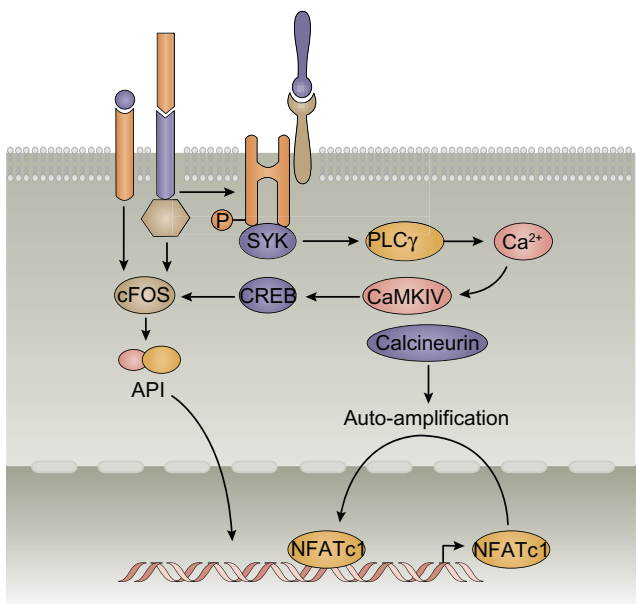

E Induction of osteoclast-specific genes

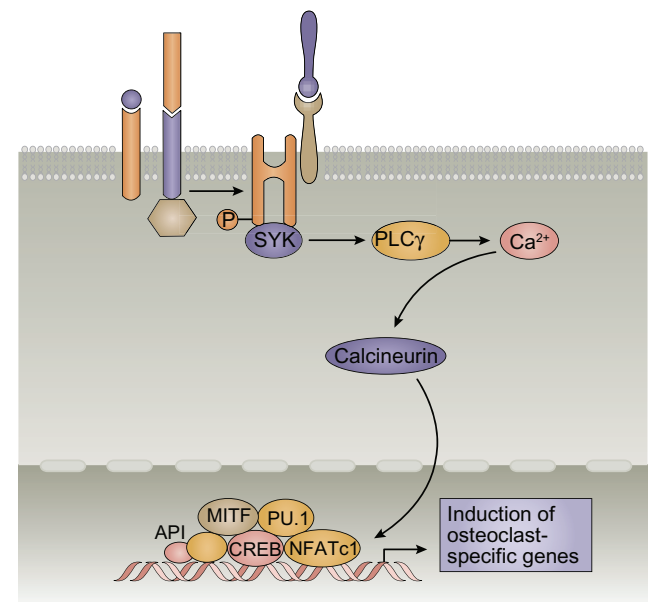

Figure I Osteoclast differentiation is induced by macrophage colony-stimulating factor (M-CSF), receptor activator of nuclear factor- $\mathrm{B} B[N F-\kappa B]$ ligand (RANKL) and its costimulatory factor, immunoglobulin (lg)-like receptor. (A) Precursor-cell stage. The binding of M-CSF to its receptor, cFMS, activates the proliferation and survival of osteoclast precursor cells of the monocyte-macrophage lineage that express receptor activator of nuclear factor- $\kappa B$ (RANK). The costimulatory receptors might be stimulated from early stages, although ligands of costimulatory receptors have yet to be identified. (B) Proximal RANK signals. RANKL binding to RANK results in the recruitment of tumor-necrosis-factor-receptor-associated factor 6 (TRAF6). At the same time, RANK activation results in the phosphorylation of the immunoreceptor tyrosine-based activation motif (ITAM) in DAPI2 and Fc-receptor common $\gamma$-subunit (FcR $\gamma)$, both of which are adaptor proteins associating with distinct Ig-like receptors. Ig-like receptor signals are called costimulatory signals for RANK. (C) Initial induction of nuclear factor of activated T cells, cytoplasmic I (NFATcl). NFATcl, a key transcription factor for osteoclastogenesis, is initially induced by TRAF6-activated NF-KB and NFATc2 that is present in the cell before RANKL stimulation. Phosphorylation of the ITAM in DAPI2 (or FcR $\gamma$ ) results in the recruitment of spleen tyrosine kinases (SYKs) that activate calcium signaling through phospholipase C $\gamma$ (PLC $\gamma$ ). (D) Auto amplification of NFATcl. Calcium signal-mediated persistent activation of NFATcl, as well as cooperation with activator protein I (API), is a prerequisite for the robust induction of NFATcl. API activation is mediated by the induction and activation of cFOS by calcium/calmodulin-dependent protein kinase type IV (CaMKIV)-stimulated cyclic adenosine monophosphate responsive-element-binding protein (CREB) and cFMS. The NFATcl promoter is epigenetically activated through histone acetylation and NFATcl binds to an NFAT-binding site of its own promoter. (E) In the nucleus, NFATcI works together with other transcription factors, such as API, PU.I, microphthalmia-associated transcription factor (MITF) and CREB, to induce various osteoclast-specific genes, including tartrate-resistant acid phosphatase, cathepsin $\mathrm{K}$, and calcitonin receptor.

Note: Reprinted by permission from Macmillan Publishers Ltd: Nature Review Immunology, H Takayanagi, Osteoimmunology: shared mechanisms and crosstalk between the immune and bone systems, 7(4):292-304, copyright 2007. ${ }^{29}$

Therefore, for bone remodeling after fracture, MSCs are recruited within lesions and induced to form new bone via both endochondral and intramembranous ossification. ${ }^{3}$ Whether healing of a fracture or other injury occurs following an endochondral or intramembranous pathway is dependent on the sensitivity to the mechanical environment to which the injury is subjected. ${ }^{2}$ During bone formation, Indian hedgehog (Ihh) acts at a very early stage to induce the expression of Runx2, which needs to be phosphorylated to be active. ${ }^{3}$
BMPs are also necessary to lead osteoblastic commitment and to drive osteoblastic maturation, notably through Runx2 and distal-less homeobox 5 protein (Dlx5) induction. ${ }^{3}$ Mitogen-activated protein kinase can phosphorylate Dlx 5 and Runx $2 .{ }^{3}$ The osteochondroblastic progenitors can express Ihh, which induces secretion of parathyroid hormone (PTH)related protein and acts on preosteoblastic cells (positive for collagen 1a1, alkaline phosphatase, and PTH receptor 1 (PTH-R1) to increase their maturation. ${ }^{3}$ Msh homeobox 2 


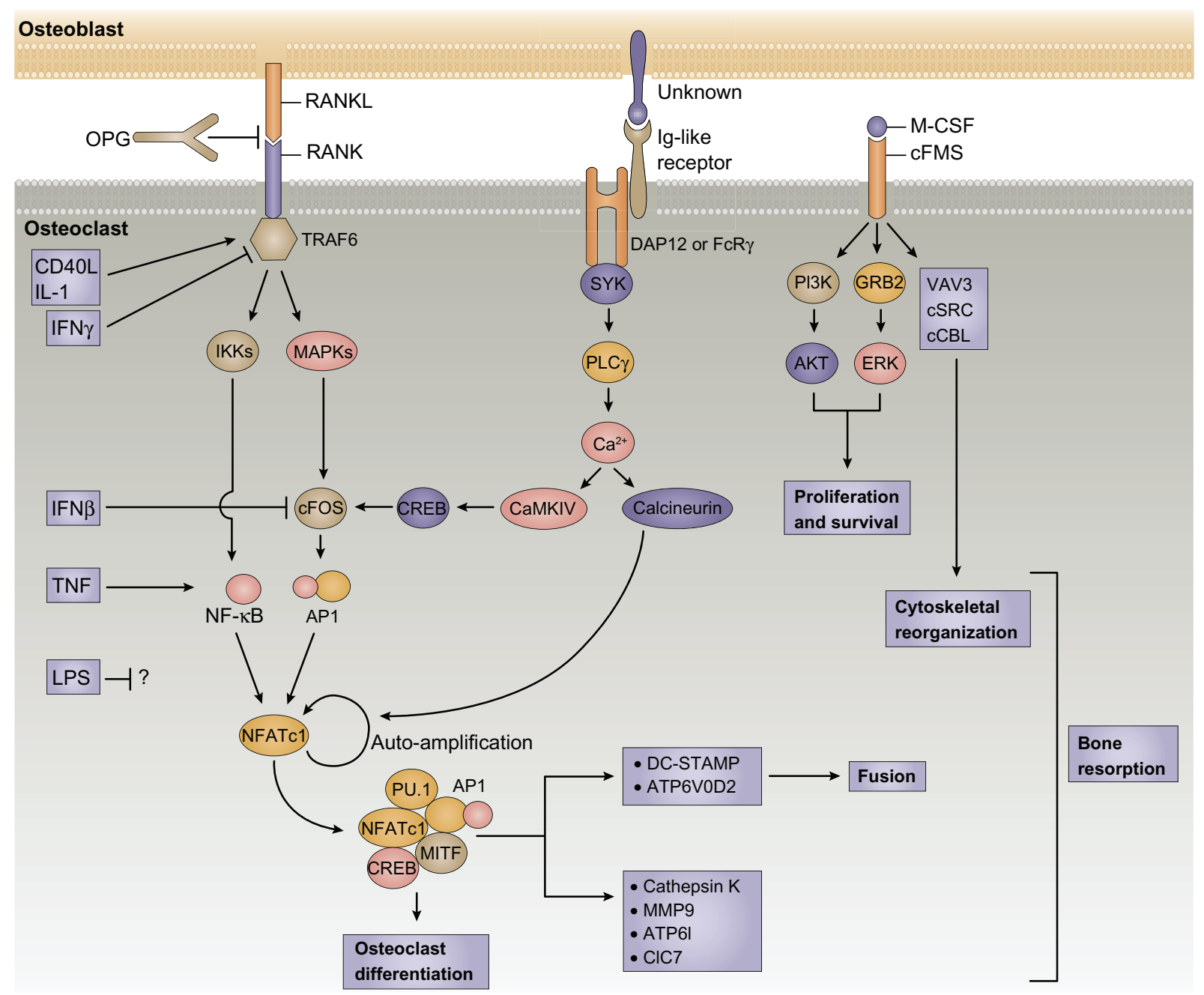

Figure 2 The immune and skeletal systems share cytokines, receptors, signaling molecules, and transcription factors, all of which cooperatively regulate osteoclasts and osteoblasts as well as their interactions. Osteoblasts regulate osteoclastogenesis through receptor activator of nuclear factor- $\kappa B$ (NF- $\kappa B$ ) ligand (RANKL)-receptor activator of nuclear factor-KB (RANK) (and its decoy receptor osteoprotegerin [OPG]) interactions, macrophage colony-stimulating factor (M-CSF)-cFMS interactions and immunoglobulin (Ig)-like receptors associated with immunoreceptor tyrosine-based activation motif-harboring adaptor molecules (such as DAPI 2 and Fc-receptor common $\gamma$-subunit [FcR $\gamma$ ], the ligands of which are not well characterized). Although not depicted, semaphorin 6D, and its receptor plexin AI, and ephrin receptor B4 and ephrin B2 were newly identified as mediators of osteoblast-osteoclast interactions. There are extensive signaling pathways in osteoclasts. RANK and lg-like receptors stimulate downstream signaling cascades (such as tumor necrosis factor [TNF] receptor-associated factor 6 [TRAF6], NF-kB, mitogen-activated protein kinases [MAPKs], activator protein I [API], calcineurin, and nuclear factor of activated T cells cytoplasmic I [NFATcI]), which are influenced by a number of immunoregulatory molecules including CD40 ligand (CD40L), interleukin-I (IL-I), interferon- $\beta$ (IFN $\beta$ ), IFN $\gamma$, TNF, and lipopolysaccharide (LPS). Dendritic-cell-specific transmembrane protein (DC-STAMP) and ATP6VOD2 are necessary for the fusion of osteoclast precursor cells. Phosphoinositide 3-kinase (PI3K)-AKT and growth-factor-receptor-bound protein 2-extracellularsignal-regulated kinase (GRB2-ERK) pathways are important for the proliferation and survival of the osteoclast lineage, whereas VAV3, cSRC, and Casitas B-lineage lymphoma (CCBL) are included in the molecules required for cytoskeletal reorganization and bone-resorbing osteoclasts. Osteoclast activity is dependent on acidifying proton pump ATP6I and chloride channel 7 (CIC7), as well as matrix-degrading enzymes such as cathepsin K and matrix metalloproteinase 9 (MMP9). The following molecules are known to be involved in both the bone system and the immune system: NF-KB, RANKL, RANK, OPG, cFMS, M-CSF, Ig-like receptors, FcR $\gamma$, DAPI2, TRAF6, MAPKs, API, calcineurin, NFATcI, CD40L, IL-I, IFN $\gamma$, IFN $\beta$, TNF, LPS, DC-STAMP, PI3K, AKT, ERK, VAV3, cSRC, and cCBL.

Note: Reprinted by permission from Macmillan Publishers Ltd: Nature Review Immunology, H Takayanagi, Osteoimmunology: shared mechanisms and crosstalk between the immune and bone systems, 7(4):292-304, copyright 2007. ${ }^{29}$

Abbreviations: CaMKIV, calcium/calmodulin-dependent protein kinase type IV; CREB, cyclic adenosine monophosphate responsive-element-binding protein; PLC, phospholipase C; MITF, microphthalmia-associated transcription factor; IKK, inhibitor of NF-KB (IKB) kinase; SYK, spleen tyrosine kinase.

(Msx2) is a factor preferentially found within proliferative progenitors, whereas Dlx5 leads to maturation. ${ }^{3}$ In addition, Dlx 5 and Msx 2 compete for DNA binding. ${ }^{3}$ Therefore, the Dlx5:Msx2 content drives the maturation of cells. ${ }^{3}$ In addition, Msx2 induces apoptosis in later stages of maturation. ${ }^{3}$ Wnt proteins can induce the proliferation of osteochondroblastic progenitors and preosteoblasts. ${ }^{3}$ When osteoblasts mature, they can express Wnt inhibitors such as Dickkopf-related protein 1 molecules. ${ }^{3}$ Osteoclasts are capable of degrading mineralized bone and are hematopoietic-derived cells. ${ }^{3}$ They are generated through RANKL and macrophage colony-stimulating factor cytokines secreted by activated T- and B-lymphocytes 
and by preosteoblasts. ${ }^{3}$ Osteoclast activities can be regulated by interleukin-10 and by osteoprotegerin, a decoy receptor of RANKL. ${ }^{3}$ Osteoprotegerin is preferentially expressed by mature osteoblasts (positive for osteocalcin; bone sialoprotein; PTH-R1; and osteonectin, also referred to as SPARC). ${ }^{3}$ Finally, degradation of the bone matrix releases several cytokines and growth factors, such as BMPs and insulin-like growth factor, which in turn can activate immature cells (Figure 3 ). ${ }^{3}$

\section{Scaffolds}

While supporting osteogenesis and osteoconduction, an ideal scaffold should also provide mechanical stability and support the necessary cell activity that leads to bone regrowth. ${ }^{2}$ Important scaffold properties to consider include porosity, pore size, geometry, and material. Adequate porosity is essential for the infiltration of cells and the formation of blood vessels at the new bone. ${ }^{40}$

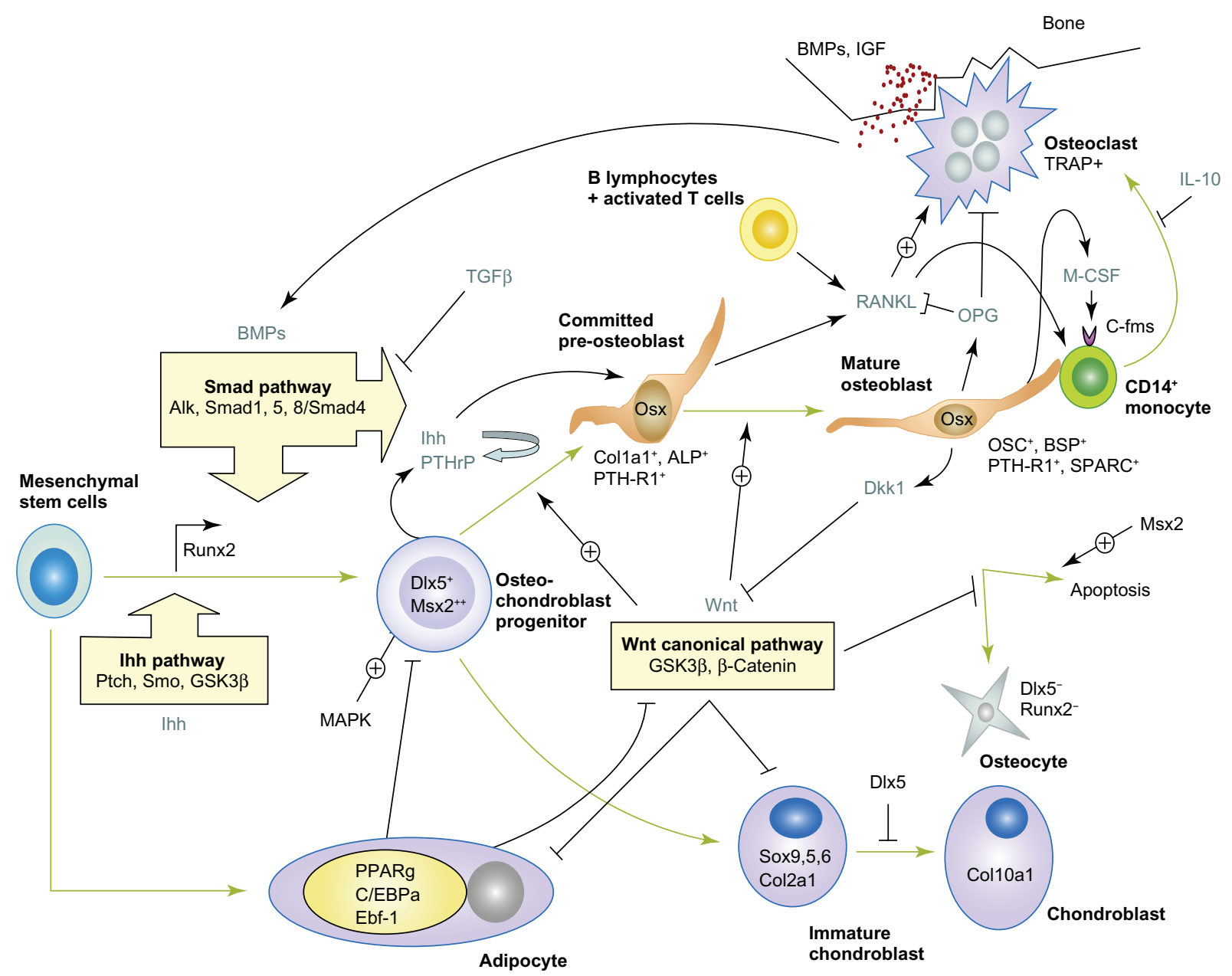

Figure 3 Bone remodeling after fracture. Mesenchymal stem cells are recruited within lesions and induced to form new bone following both endochondral and intramembranous pathways. During bone formation, Indian hedgehog (lhh) acts at a very early stage to induce the expression of runt-related transcription factor 2 (Runx2), which needs to be phosphorylated to be active. Bone morphogenetic proteins (BMPs) are also necessary to lead osteoblastic commitment and to drive osteoblastic maturation, notably through Runx2 and distal-less homeobox 5 (Dlx5) induction. Mitogen-activated protein kinase (MAPK) can phosphorylate Dlx5 and Runx2. The osteochondroblastic progenitors can express Ihh, which induces secretion of parathyroid hormone-related protein (PTHrP) and also acts on preosteoblastic cells positive for collagen Ial (collal), alkaline phosphatase (ALP), and PTH receptor I (PTH-RI) to increase their maturation. Msh homeobox 2 (Msx2) is a factor preferentially found within proliferative progenitors, whereas Dlx5 leads to maturation. In addition, Dlx5 and Msx2 compete for DNA binding. Therefore, the Dl 55 :Ms $\times 2$ content drives the maturation of cells. In addition, Msx2 induces apoptosis in later stages of maturation. Wnt proteins can induce the proliferation of osteochondroblastic progenitors and preosteoblasts. When osteoblasts mature, they can express Wnt inhibitors such as Dickkopf-related protein I (Dkkl) molecules. Osteoclasts are capable of degrading mineralized bone and are hematopoietic-derived cells. They are generated through receptor activator of nuclear kappa-B ligand (RANKL) and macrophage colonystimulating factor (M-CSF) cytokines secreted by activated T- and B-lymphocytes and by preosteoblasts. Osteoclast activities can be regulated by interleukin- 10 (IL- I0) and by osteoprotegerin (OPG), a decoy receptor of RANKL. OPG is preferentially expressed by mature osteoblasts (positive for osteocalcin [OSC], bone sialoprotein [BSP], PTH-RI, and osteonectin [SPARC]). Finally, degradation of the bone matrix releases several cytokines and growth factors, such as BMPs and insulin-like growth factor (IGF), which in turn can activate immature cells.

Note: Reprinted and modified by permission from Trends in Molecular Medicine, F Deschaseaux, L Sensebe, D Heymann, Mechanisms of bone repair and regeneration, Vol. 15, Issue 9, Pages 417-429, Copyright 1999, with permission from Elsevier. ${ }^{3}$

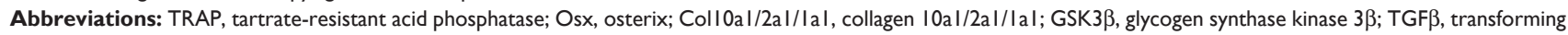
growth factor $\beta$; PPARg, peroxisome proliferator-activated receptor gamma; C/EBPa, CCAAT-enhancer-binding protein alpha. 
Previous experiments found improved in vivo osteogenesis by using BMP-2-loaded hydroxyapatite scaffolds with high porosity, which allowed for cell recruitment and vascularization. . $^{2,41,42}$

Scaffold geometry is another important factor for successful osteogenesis. It dictates cell adhesion, proliferation, and differentiation as well as nutrient and oxygen availability. An experiment by Kilian et al concluded that geometry is important for producing an osteogenic pathway. ${ }^{43}$ They found that geometric features that increase actomyosin contractility promote osteogenesis through Wnt signaling and other pathways. ${ }^{43}$ They also discovered that a stiff underlying matrix in MSC cultures led to enhanced osteogenesis, most likely because the environment closely resembled that of bone in vivo. The nature of the scaffold's surface has important implications for bone tissue formation. The bone-implant interface has been shown to positively correlate with an increasing roughness of the implant surface. ${ }^{44}$ Similarly, surface microcavities on a scaffold were shown to support a more vigorous osteogenic response from dental pulp-derived stromal stem cells. ${ }^{45}$

When selecting the appropriate material for a scaffold, several elements need to be considered, such as the material's composition, degradation rate, and the strength it affords the scaffold. Current options for materials are natural or synthetic polymers (ie, polytetrafluoroethylene), bioactive materials (ie, bioactive glass), and osteophilic materials such as hydroxyapatite ceramics or composites. ${ }^{46}$ Animal studies have shown that the best procedure by which MSCs can induce bone formation is via an injection or implant with the use of a natural or synthetic scaffold. ${ }^{9,47,48}$ The natural or synthetic polymers become encapsulated by fibrous tissue and their high molecular weight results in slower degradation and improved mechanical strength. ${ }^{46,47,49,50}$ The poly(lactic-co-glycolic acid) polymer is a popular scaffold choice as it is infrequently rejected and does not cause inflammation, therefore, it has excellent biocompatibility. ${ }^{45}$ Bioactive materials chemically modify the surface of bone by forming a layer of hydroxyapatite and bind directly to the bone. ${ }^{46,51}$ For this reason, their use is limited to nonbearing applications. Osteophilic materials can directly apposition themselves to bone given their biocompatibility and high protein-binding affinity. ${ }^{46}$ Both of these qualities make them good vehicles for drug delivery. However, their use is also restricted to non-load-bearing sites as they fail readily due to their brittleness. ${ }^{46,52}$ Collagen carriers used in conjunction with ceramics such as hydroxyapatite and $\beta$-tricalcium phosphate have been used to deliver BMP-7 in spinal fusion and have been shown to perform similarly to bone autografts. ${ }^{46,53}$

A scaffold's degradation rate is determined by its chemical and structural properties as well as many in vivo factors including $\mathrm{pH}$, temperature, ionic strength, and access to vasculature. However, degradation can be dangerous resulting in the release of acidic products and a decrease in local $\mathrm{pH} .{ }^{46}$ This can cause inflammation and/or tissue necrosis, and eventual tissue dysfunction. ${ }^{46,54}$

To provide structural support and mechanical stability, a scaffold must mimic the strength and stiffness of bone. A scaffold that is too weak can fail to support the skeleton, while one that is too stiff can lead to stress shielding. ${ }^{46,52}$ Stress shielding results when the scaffold absorbs the mechanical stress, but the host bone is not stimulated enough for bone formation to occur. Thus, bone resorption continues, resulting in potential lysis around the implant. The appropriate combination of soluble factors and biomaterials will result in the most efficient and effective tissue regeneration.

\section{Clinical application of MSCs}

Bone autografts have been used for centuries in reconstructive surgery, as well as in orthopedic surgery, as unvascularized free grafts. Also, they have been grafted with vessels that require microanastomosis to maintain cellular viability in the graft to facilitate osteogenesis. Bone marrow has been used in a similar way to autologous bone grafts, both containing osteoblast precursors. ${ }^{46}$ Autologous marrow can be aspirated from the iliac crest and injected percutaneously into osseous defects. ${ }^{46,55}$ In 2005 , Hernigou et al successfully used bone marrow cells that were isolated during surgery and concentrated them prior to implantation. ${ }^{46,56}$ Colony-forming unit fibroblasts are in vitro adherent bone marrow cells that can form bone in vivo. ${ }^{46,57}$ Although single adherent cells can form colonies containing multiple lineages, including chondrocytes, osteoblasts, adipocytes, and fibroblasts, ${ }^{11,46}$ these cells are not capable of extensive self-renewal and therefore are not bona fide MSCs.

In vitro osteogenesis has been thoroughly demonstrated in monolayer culture, three-dimensional scaffolds, ${ }^{46,58-62}$ research with animal and human cells, and has been reviewed elsewhere for a variety of audiences and clinical subspecialties. ${ }^{20,46,63-66}$ A US Food and Drug Administrationapproved cell-based product for bone regeneration in the clinic remains unavailable. Currently, the Food and Drug Administration has approved only one product under the autologous cellular therapy category $\left(\mathrm{Carticel}^{\circledR}\right.$; Genzyme 
Corporation, Cambridge, MA), which is designated to be used only for articular cartilage repair. ${ }^{46}$

\section{Therapeutic applications}

MSCs show great promise for the treatment of disease and repair of injury. Their use has been explored in several physiological realms including cardiovascular repair, central nervous system or spinal cord injury, and bone and cartilage repair. Damaged myocardium has been an active experimental target for site-directed MSC therapy. In 2001, Orlic et al showed that locally delivered bone marrow cells can generate de novo myocardium, indicating a use for stem cells in treating coronary artery disease. ${ }^{67}$ Similarly, the delivery of bone marrow cells into the infarct zone in patients following myocardial infarction resulted in a dramatic improvement in global heart function. ${ }^{68}$ Following bone marrow transplantation, engraftment of bone marrowderived cardiomyocytes was observed in the adult heart. ${ }^{69}$ While MSCs and other bone marrow cells have shown improvements in myocardial function in many animal models of acute myocardial infarction, the mechanism of their effect is still unknown.

The in vivo use of stem cell-based therapy has been demonstrated for treatment of central nervous system or spinal cord injury. Two studies using a rat model of spinal cord injury have shown neurologic improvement upon site-directed application of MSCs. ${ }^{70,71}$ The MSCs are credited with the production of essential trophic factors, which not only promoted directed growth of new axons but also formed "guiding strands" that bridged the epicenter of injury. ${ }^{16}$

The most successful application of MSCs has been site-directed administration for repair of bone or cartilage. It is estimated that 1,600,000 bone grafts are performed every year to regenerate bone lost to trauma and disease, $6 \%(96,000)$ of which are craniomaxillofacial in nature. ${ }^{72}$ In a two-stage procedure, a composite MSC and a titanium/ hydroxyapatite scaffold was placed into a patient's latissimus dorsi for 7 weeks before transplantation to replace a segment of mandible. ${ }^{46}$ Although the procedure was associated with a number of technical problems, such as fracture of the titanium mesh, partial infection, and necrosis, islands of bone formation and increased bone density were documented within the transplant. ${ }^{46,73}$ Also, iliac crest MSCs injected around dental implants have been shown to result in new bone formation and osseointegration of the implants. ${ }^{46,74}$ Expanded periosteal cells were used in the reconstruction of an avulsed phalanx with porous hydroxyapatite. ${ }^{46,75}$ Follow-up at 28 months indicated retention of implant volume and structure, and evidence of lamellar bone comprising $5 \%$ of the construct volume. ${ }^{46}$

There is some clinical experience of bone reconstruction with expanded human MSCs combined with scaffolds. MSCs implanted on hydroxyapatite/tricalcium phosphate scaffolds have accelerated bone formation when placed in craniofacial defects and critical long-bone defects in small and large animal systems. ${ }^{76-78}$ Constructs of expanded autologous MSCs in macroporous hydroxyapatite were used in three patients with large segmental bone defects. ${ }^{46,79,80}$ Fusion between the implant and host bone occurred 5-7 months after surgery, with restoration of pain-free function for 6-7 years. ${ }^{46}$ A study by Horwitz et al demonstrated that allogenic bone marrow transplantation in children with osteogenesis imperfecta, a genetic bone disorder, resulted in engraftment of donor-derived MSCs and an increase in new bone formation. ${ }^{81}$

\section{Future directions}

The basic and preclinical research literature clearly indicates that the use of MSCs for the reconstruction and repair of bone is feasible. Problem areas, however, include cell numbers, an overreliance on existing scaffold materials, optimum delivery of the required factors, and the control of transgene expression. Other matters that need further attention include the elimination of fetal calf serum, untoward effects of expanding cell numbers, the commitment to or reversibility of the differentiated state, the endurance of the cells in vivo, vascularization, integration with the recipient bone, and the capacity to form bone and marrow structures in vivo.

Concerns about the relevance of in vitro studies and studies in immunodeficient animals have dampened enthusiasm about the role of bone tissue engineering in bone regeneration. It remains unclear whether the cost and complexity of cell-based tissue engineering would hamper its potential application for bone tissue. Moreover, the relevance of troubling data from mouse studies needs to be addressed. In one study, after slow initial growth, mouse MSCs suddenly proliferated rapidly and became tumorigenic. ${ }^{46,82}$ In other studies, the host-derived sarcomas developed around implants with MSCs; ${ }^{46,83}$ this was thought to be a result of the stimulation of lymphocyte expansion by MSCs and suppression of the host's antitumor immune response. ${ }^{46}$ Paracrine secretions of MSCs, therefore, could represent a double-edged sword by both inhibiting allogeneic surveillance and by promoting tumor development. Of importance, however, is that, unlike most preparations of human MSCs, the mouse MSCs were prepared from 
whole marrow and included adherent blood cells and other differentiated cells. A reassessment of circulating osteoblast progenitor cells and perivascular cells, and their contribution to bone repair, raises attractive ideas for the capitalization of inherent regenerative potential without the use of exogenous cells.

What is needed now is a greater understanding of inadequate responses to tissue injury and the potential for mobilizing innate pathways. Current thinking about biologic, regenerative medicine reemphasizes the potential of "primed" materials for stimulating, enhancing, or controlling a tissue's innate capacity for repair. Successful tissue regeneration will require the identification of tissues with the appropriate populations of cells, the best conditions for their ex vivo expansion, the optimal nature of the scaffolds and carriers used, and the development of suitable preclinical animal models. To optimize the therapeutic applications of MSCs, we must construct novel techniques that surpass the simple expansion and transplantation procedures currently in use.

\section{Disclosure}

The authors report no conflicts of interest in this work.

\section{References}

1. Ciacci J, Ho A, Ames CP, Jandial R. Stem cell horizons in intervertebral disc degeneration. Stem Cells Cloning. 2008;1:31-39.

2. Sundelacruz S, Kaplan DL. Stem cell- and scaffold-based tissue engineering approaches to osteochondral regenerative medicine. Semin Cell Dev Biol. 2009;20(6):646-655.

3. Deschaseaux F, Sensebe L, Heymann D. Mechanisms of bone repair and regeneration. Trends Mol Med. 2009;15(9):417-429.

4. Duplomb L, Dagouassat M, Jourdon P, Heymann D. Concise review: embryonic stem cells: a new tool to study osteoblast and osteoclast differentiation. Stem Cells. 2007;25(3):544-552.

5. Duplomb L, Baud'huin M, Charrier C, et al. Interleukin-6 inhibits receptor activator of nuclear factor kappaB ligand-induced osteoclastogenesis by diverting cells into the macrophage lineage: key role of Serine727 phosphorylation of signal transducer and activator of transcription 3. Endocrinology. 2008;149(7):3688-3697.

6. Kwan Tat S, Padrines M, Theoleyre S, Heymann D, Fortun Y. IL-6, RANKL, TNF-alpha/IL-1: interrelations in bone resorption pathophysiology. Cytokine Growth Factor Rev. 2004;15(1):49-60.

7. Papachroni KK, Karatzas DN, Papavassiliou KA, Basdra EK, Papavassiliou AG. Mechanotransduction in osteoblast regulation and bone disease. Trends Mol Med. 2009;15(5):208-216.

8. Ferguson C, Alpern E, Miclau T, Helms JA. Does adult fracture repair recapitulate embryonic skeletal formation? Mech Dev. 1999;87(1-2): $57-66$.

9. El Tamer MK, Reis RL. Progenitor and stem cells for bone and cartilage regeneration. J Tissue Eng Regen Med. 2009;3(5):327-337.

10. Glowacki J. The deceiving appearances of osteoclasts. $N$ Engl J Med. 2009;360(1):80-82.

11. Pittenger MF, Mackay AM, Beck SC, et al. Multilineage potential of adult human mesenchymal stem cells. Science. 1999;284(5411):143-147.

12. Meijer GJ, de Bruijn JD, Koole R, van Blitterswijk CA. Cell-based bone tissue engineering. PLoS Med. 2007;4(2):e9.
13. Barry FP, Murphy JM. Mesenchymal stem cells: clinical applications and biological characterization. Int J Biochem Cell Biol. 2004;36(4): $568-584$.

14. Lennon DP, Haynesworth SE, Bruder SP, Jaiswal N, Caplan AI. Human and animal mesenchymal progenitor cells from bone marrow: Identification of serum for optimal selection and proliferation. In Vitro Cell Dev Biol Anim. 1996;32(10):602-611.

15. Jaiswal N, Haynesworth SE, Caplan AI, Bruder SP. Osteogenic differentiation of purified, culture-expanded human mesenchymal stem cells in vitro. J Cell Biochem. 1997;64(2):295-312.

16. Javazon EH, Beggs KJ, Flake AW. Mesenchymal stem cells: paradoxes of passaging. Exp Hematol. 2004;32(5):414-425.

17. Owen M, Friedenstein AJ. Stromal stem cells: marrow-derived osteogenic precursors. Ciba Found Symp. 1988;136:42-60.

18. Digirolamo CM, Stokes D, Colter D, Phinney DG, Class R, Prockop DJ. Propagation and senescence of human marrow stromal cells in culture: a simple colony-forming assay identifies samples with the greatest potential to propagate and differentiate. Br J Haematol. 1999;107(2): $275-281$.

19. Togel F, Westenfelder C. Adult bone marrow-derived stem cells for organ regeneration and repair. Dev Dyn. 2007;236(12):3321-3331.

20. Arthur A, Zannettino A, Gronthos S. The therapeutic applications of multipotential mesenchymal/stromal stem cells in skeletal tissue repair. J Cell Physiol. 2009;218(2):237-245.

21. Chamberlain G, Fox J, Ashton B, Middleton J. Concise review: mesenchymal stem cells: their phenotype, differentiation capacity, immunological features, and potential for homing. Stem Cells. 2007; 25(11):2739-2749.

22. Steck E, Bertram H, Abel R, Chen B, Winter A, Richter W. Induction of intervertebral disc-like cells from adult mesenchymal stem cells. Stem Cells. 2005;23(3):403-411.

23. Richardson SM, Curran JM, Chen R, et al. The differentiation of bone marrow mesenchymal stem cells into chondrocyte-like cells on poly-Llactic acid (PLLA) scaffolds. Biomaterials. 2006;27(22):4069-4078.

24. Sekiya I, Larson BL, Smith JR, Pochampally R, Cui JG, Prockop DJ. Expansion of human adult stem cells from bone marrow stroma: conditions that maximize the yields of early progenitors and evaluate their quality. Stem Cells. 2002;20(6):530-541.

25. Erices A, Conget P, Minguell JJ. Mesenchymal progenitor cells in human umbilical cord blood. Br J Haematol. 2000;109(1):235-242.

26. Gang EJ, Hong SH, Jeong JA, et al. In vitro mesengenic potential of human umbilical cord blood-derived mesenchymal stem cells. Biochem Biophys Res Commun. 2004;321(1):102-108.

27. Fukuchi Y, Nakajima H, Sugiyama D, Hirose I, Kitamura T, Tsuji K. Human placenta-derived cells have mesenchymal stem/progenitor cell potential. Stem Cells. 2004;22(5):649-658.

28. Im GI, Shin YW, Lee KB. Do adipose tissue-derived mesenchymal stem cells have the same osteogenic and chondrogenic potential as bone marrow-derived cells? Osteoarthritis Cartilage. 2005;13(10):845-853.

29. Takayanagi H. Osteoimmunology: shared mechanisms and crosstalk between the immune and bone systems. Nat Rev Immunol. 2007;7(4): 292-304.

30. Seeman E, Delmas PD. Bone quality - the material and structural basis of bone strength and fragility. N Engl J Med. 2006;354(21):2250-2261.

31. Harada S, Rodan GA. Control of osteoblast function and regulation of bone mass. Nature. 2003;423(6937):349-355.

32. Karsenty G, Wagner EF. Reaching a genetic and molecular understanding of skeletal development. Dev Cell. 2002;2(4):389-406.

33. Nakashima K, Zhou X, Kunkel G, et al. The novel zinc finger-containing transcription factor osterix is required for osteoblast differentiation and bone formation. Cell. 2002;108(1):17-29.

34. Boyle WJ, Simonet WS, Lacey DL. Osteoclast differentiation and activation. Nature. 2003;423(6937):337-342.

35. Suda T, Takahashi N, Udagawa N, Jimi E, Gillespie MT, Martin TJ. Modulation of osteoclast differentiation and function by the new members of the tumor necrosis factor receptor and ligand families. Endocr Rev. 1999;20(3):345-357. 
36. Takayanagi $\mathrm{H}$. Mechanistic insight into osteoclast differentiation in osteoimmunology. J Mol Med (Berl). 2005;83(3):170-179.

37. Asagiri M, Takayanagi $\mathrm{H}$. The molecular understanding of osteoclast differentiation. Bone. 2007;40(2):251-264.

38. Theill LE, Boyle WJ, Penninger JM. RANK-L and RANK: T cells, bone loss, and mammalian evolution. Annu Rev Immunol. 2002;20: $795-823$.

39. Teitelbaum SL, Ross FP. Genetic regulation of osteoclast development and function. Nat Rev Genet. 2003;4(8):638-649.

40. Bessa PC, Casal M, Reis RL. Bone morphogenetic proteins in tissue engineering: the road from laboratory to clinic, part II (BMP delivery). J Tissue Eng Regen Med. 2008;2(2-3):81-96.

41. Roy TD, Simon JL, Ricci JL, Rekow ED, Thompson VP, Parsons JR. Performance of degradable composite bone repair products made via three-dimensional fabrication techniques. J Biomed Mater Res A. 2003; 66(2):283-291.

42. Karageorgiou V, Kaplan D. Porosity of 3D biomaterial scaffolds and osteogenesis. Biomaterials. 2005;26(27):5474-5491.

43. Kilian KA, Bugarija B, Lahn BT, Mrksich M. Geometric cues for directing the differentiation of mesenchymal stem cells. Proc Natl Acad Sci U S A. 2010;107(11):4872-4877.

44. Buser D, Schenk RK, Steinemann S, Fiorellini JP, Fox CH, Stich H. Influence of surface characteristics on bone integration of titanium implants. A histomorphometric study in miniature pigs. J Biomed Mater Res. 1991;25(7):889-902.

45. Graziano A, d'Aquino R, Cusella-De Angelis MG, et al. Concave pit-containing scaffold surfaces improve stem cell-derived osteoblast performance and lead to significant bone tissue formation. PLoS One. 2007;2(6):e496.

46. Bueno EM, Glowacki J. Cell-free and cell-based approaches for bone regeneration. Nat Rev Rheumatol. 2009;5(12):685-697.

47. Cancedda R, Dozin B, Giannoni P, Quarto R. Tissue engineering and cell therapy of cartilage and bone. Matrix Biol. 2003;22(1): 81-91.

48. Richards M, Huibregtse BA, Caplan AI, Goulet JA, Goldstein SA. Marrow-derived progenitor cell injections enhance new bone formation during distraction. J Orthop Res. 1999;17(6):900-908.

49. Braunecker J, Baba M, Milroy GE, Cameron RE. The effects of molecular weight and porosity on the degradation and drug release from polyglycolide. Int J Pharm. 2004;282(1-2):19-34.

50. Thomson RC, Yaszemski MJ, Powers JM, Mikos AG. Fabrication of biodegradable polymer scaffolds to engineer trabecular bone. J Biomater Sci Polym Ed. 1995;7(1):23-38.

51. Oonishi H, Hench LL, Wilson J, et al. Quantitative comparison of bone growth behavior in granules of Bioglass, A-W glass-ceramic, and hydroxyapatite. J Biomed Mater Res. 2000;51(1):37-46.

52. Khan Y, Yaszemski MJ, Mikos AG, Laurencin CT. Tissue engineering of bone: material and matrix considerations. J Bone Joint Surg Am. 2008;90 Suppl 1:36-42.

53. Delecrin J, Takahashi S, Gouin F, Passuti N. A synthetic porous ceramic as a bone graft substitute in the surgical management of scoliosis: a prospective, randomized study. Spine (Phila Pa 1976). 2000;25(5): $563-569$.

54. Temenoff JS, Lu L, Mikos AG. Bone tissue engineering using synthetic biodegradable polymer scaffolds. In: Davies JE, editor. Bone Engineering. Toronto: EM Squared Incorporated; 2000. p. 454-461.

55. Connolly JF, Guse R, Tiedeman J, Dehne R. Autologous marrow injection for delayed unions of the tibia: a preliminary report. J Orthop Trauma. 1989;3(4):276-282.

56. Hernigou P, Poignard A, Manicom O, Mathieu G, Rouard H. The use of percutaneous autologous bone marrow transplantation in nonunion and avascular necrosis of bone. J Bone Joint Surg Br. 2005;87(7): 896-902.

57. Friedenstein AJ, Piatetzky-Shapiro II, Petrakova KV. Osteogenesis in transplants of bone marrow cells. J Embryol Exp Morphol. 1966;16(3): 381-390.
58. Lisignoli G, Fini M, Giavaresi G, Nicoli AN, Toneguzzi S, Facchini A. Osteogenesis of large segmental radius defects enhanced by basic fibroblast growth factor activated bone marrow stromal cells grown on non-woven hyaluronic acid-based polymer scaffold. Biomaterials. 2002;23(4):1043-1051.

59. Datta N, Holtorf HL, Sikavitsas VI, Jansen JA, Mikos AG. Effect of bone extracellular matrix synthesized in vitro on the osteoblastic differentiation of marrow stromal cells. Biomaterials. 2005;26(9):971-977.

60. Yamada Y, Ueda M, Naiki T, Takahashi M, Hata K, Nagasaka T. Autogenous injectable bone for regeneration with mesenchymal stem cells and platelet-rich plasma: tissue-engineered bone regeneration. Tissue Eng. 2004;10(5-6):955-964.

61. Sikavitsas VI, Bancroft GN, Holtorf HL, Jansen JA, Mikos AG. Mineralized matrix deposition by marrow stromal osteoblasts in 3D perfusion culture increases with increasing fluid shear forces. Proc Natl Acad Sci U S A. 2003;100(25):14683-14688.

62. Lu HH, El-Amin SF, Scott KD, Laurencin CT. Three-dimensional, bioactive, biodegradable, polymer-bioactive glass composite scaffolds with improved mechanical properties support collagen synthesis and mineralization of human osteoblast-like cells in vitro. J Biomed Mater $\operatorname{Res} A$. 2003;64(3):465-474.

63. Abdallah BM, Kassem M. The use of mesenchymal (skeletal) stem cells for treatment of degenerative diseases: current status and future perspectives. J Cell Physiol. 2009;218(1):9-12.

64. Lee K, Chan CK, Patil N, Goodman SB. Cell therapy for bone regeneration-bench to bedside. J Biomed Mater Res B Appl Biomater. 2009;89(1):252-263.

65. Sterodimas A, De Faria J, Correa WE, Pitanguy I. Tissue engineering in plastic surgery: an up-to-date review of the current literature. Ann Plast Surg. 2009;62(1):97-103.

66. Robey PG, Bianco P. The use of adult stem cells in rebuilding the human face. J Am Dent Assoc. 2006;137(7):961-972.

67. Orlic D, Kajstura J, Chimenti S, Bodine DM, Leri A, Anversa P. Bone marrow stem cells regenerate infarcted myocardium. Pediatr Transplant. 2003; 7 Suppl 3:86-88.

68. Stamm C, Westphal B, Kleine HD, et al. Autologous bone-marrow stem-cell transplantation for myocardial regeneration. Lancet. 2003; 361(9351):45-46.

69. Deb A, Wang S, Skelding KA, Miller D, Simper D, Caplice NM. Bone marrow-derived cardiomyocytes are present in adult human heart: a study of gender-mismatched bone marrow transplantation patients. Circulation. 2003;107(9):1247-1249.

70. Hofstetter CP, Schwarz EJ, Hess D, et al. Marrow stromal cells form guiding strands in the injured spinal cord and promote recovery. Proc Natl Acad Sci U SA. 2002;99(4):2199-2204.

71. Chopp M, Zhang XH, LiY, et al. Spinal cord injury in rat: treatment with bone marrow stromal cell transplantation. Neuroreport. 2000;11(13): 3001-3005.

72. Einhorn TA. Basic science of bone graft substitutes. Annual Meeting of the Orthopaedic Trauma Association; 2003 Oct 8; Salt Lake City, UT. Available from: http://www.hwbf.org/ota/am/ota03/bssf/OTA03BG1. htm. Accessed August 8, 2011.

73. Warnke PH, Wiltfang J, Springer I, et al. Man as living bioreactor: fate of an exogenously prepared customized tissue-engineered mandible. Biomaterials. 2006;27(17):3163-3167.

74. Vacanti CA, Bonassar LJ, Vacanti MP, Shufflebarger J. Replacement of an avulsed phalanx with tissue-engineered bone. $N$ Engl J Med. 2001;344(20):1511-1514

75. Ueda M, Yamada Y, Kagami H, Hibi H. Injectable bone applied for ridge augmentation and dental implant placement: human progress study. Implant Dent. 2008;17(1):82-90.

76. De Kok IJ, Peter SJ, Archambault M, et al. Investigation of allogeneic mesenchymal stem cell-based alveolar bone formation: preliminary findings. Clin Oral Implants Res. 2003;14(4):481-489.

77. Mankani MH, Kuznetsov SA, Fowler B, Kingman A, Robey PG. In vivo bone formation by human bone marrow stromal cells: effect of carrier particle size and shape. Biotechnol Bioeng. 2001;72(1):96-107. 
78. Tsuchida H, Hashimoto J, Crawford E, Manske P, Lou J. Engineered allogeneic mesenchymal stem cells repair femoral segmental defect in rats. J Orthop Res. 2003;21(1):44-53.

79. Quarto R, Mastrogiacomo M, Cancedda R, et al. Repair of large bone defects with the use of autologous bone marrow stromal cells. $N$ Engl J Med. 2001;344(5):385-386.

80. Marcacci M, Kon E, Moukhachev V, et al. Stem cells associated with macroporous bioceramics for long bone repair: 6- to 7-year outcome of a pilot clinical study. Tissue Eng. 2007;13(5):947-955.
81. Horwitz EM, Prockop DJ, Fitzpatrick LA, et al. Transplantability and therapeutic effects of bone marrow-derived mesenchymal cells in children with osteogenesis imperfecta. Nat Med. 1999;5(3):309-313.

82. Tolar J, Nauta AJ, Osborn MJ, et al. Sarcoma derived from cultured mesenchymal stem cells. Stem Cells. 2007;25(2):371-379.

83. Tasso R, Augello A, Carida M, et al. Development of sarcomas in mice implanted with mesenchymal stem cells seeded onto bioscaffolds. Carcinogenesis. 2009;30(1):150-157.

\section{Publish your work in this journal}

Biologics: Targets \& Therapy is an international, peer-reviewed journal focusing on the patho-physiological rationale for and clinical application of Biologic agents in the management of autoimmune diseases, cancers or other pathologies where a molecular target can be identified. This journal is indexed on PubMed Central, CAS, EMBase, Scopus

\section{Dovepress}

and the Elsevier Bibliographic databases. The manuscript management system is completely online and includes a very quick and fair peerreview system, which is all easy to use. Visit http://www.dovepress. com/testimonials.php to read real quotes from published authors. 